\title{
Composition chimique et valeur nutritionnelle pour les ruminants des pulpes de chicorées
}

\author{
J Verheggen, A Théwis, JM Moureaux, S Chabi
}

Faculté des sciences agronomiques, passage des Déportés, 2, 5030 Gembloux, Belgique

La culture de la chicorée (Cichorium intybus L) pour la production d'inuline et de fructose se développe en Europe. Après extraction du sucre, il subsiste un sous-produit, la pulpe, dont nous étudions ici la valeur nutritionnelle.

Cinq lots de pulpes de chicorées issus de 2 sucreries et de 3 campagnes de récolte sont analysés pour la matière sèche (MS), les cendres totales (CT), les matières azotées totales (MAT), la cellulose brute $(C B)$ et l'extrait éthéré (EE). Ca

Tableau I. Composition chimique et coefficients de digestibilité $(C D)$ comparés des pulpes déshydratées de chicorées $(\bar{x} \pm s d)$ et de betteraves.

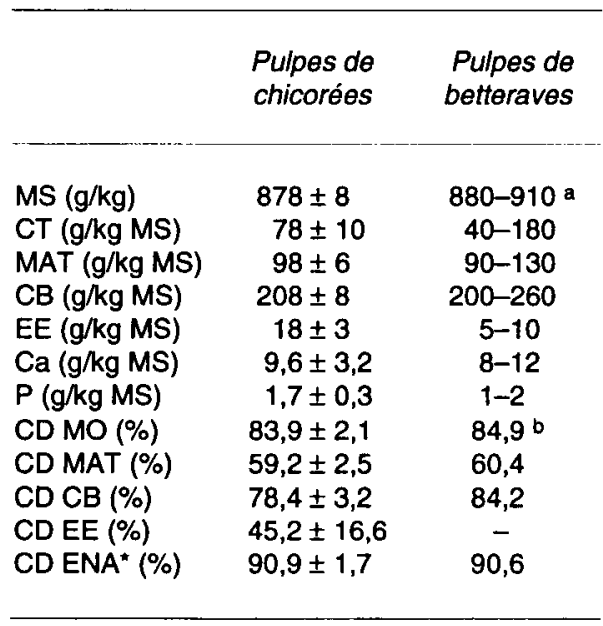

" ENA: extractif non azoté; a Focant et al(1987); b Boucqué et al (1985). est mesuré par absorption atomique et $\mathrm{P}$ par colorimétrie. La digestibilité des constituants de la pulpe de chicorées est mesurée par la méthode des différences sur 4 béliers recevant $40 \mathrm{~g} \mathrm{MS} / \mathrm{kg}$ P0,75 soit de foin et de tourteau de soja (92/8 $w / w)$, soit de ce même mélange et de pulpes $(20 / 80 \mathrm{w} / \mathrm{w})$. La valeur énergétique des pulpes est calculée à partir des valeurs de digestibilité et de la teneur en énergie brute.

La composition chimique et la digestibilité moyennes des pulpes de chicorées, comparées à celles des pulpes de betteraves, sont données au tableau I. Á l'exception de l'EE, la composition des pulpes de chicorées est comparable à celle des pulpes de betteraves belges (Focant et al, 1987) et est peu variable. L'ingestion des rations par les ovins n'a pas posé de problème particulier. Les digestibilités sont comparables à celles des pulpes de betteraves sauf celle de la cellulose. La valeur énergétique des pulpes de chicorées est de 1,04 UFL/kg MS et de 1,02 UFV $/ \mathrm{kg}$ MS.

En conclusion, la composition chimique, la digestibilité et la valeur alimentaire des pulpes de chicorées sont proches de celles des pulpes de betteraves. Leur ingestion et utilisation métabolique demandent toutefois à être étudiées.

Boucqué CV, Cottyn BG, Fiems LO, Buysse FX (1985) In: Feeding Value of By-Products and their Use by Beef Cattle, CEC Report, EUR 8918 EN, 143-158

Focant M, Allart B, Meurens M, Vanbelle M (1987) Étude de la valeur alimentaire des pulpes déshydratées de betteraves belges, IRSIA (Bruxelles), $92 \mathrm{p}$ 